\title{
The Usage of Polygraph Method in Bulgaria.
}

Todor Todorov*

Assess Ltd., 1407 Sofia, Bulgaria

*Corresponding Author: Todor Todorov, Assess Ltd, 1407 Sofia, Bulgaria, Tel: +0892 283542, E-mail: polygraph@assess.bg

Received date: July 25, 2016, Accepted date: August 11, 2016, Published date: August 18, 2016

Copyright: (c) 2016 Todorov T. This is an open access article distributed under the terms of the Creative Commons Attribution License, which permits unrestricted use, distribution, and reproduction in any medium, provided the original author and source are credited.

Citation: Todorov T (2016) The Usage of Polygraph Method in Bulgaria. J Forensic Res 7: 334. doi:10.4172/2157-7145.1000334

\section{Letter to Editor}

In the last 30 years the interest in reliable lie detection methods in Bulgaria grew. Probably one of the most widely spread, in both governmental structures and the private sector, is the polygraph method [1]. 99 percent of all examiners in Bulgaria, government employees and private sector examiners use the Backster ZCT technique since it has given the best results in practice through the years. Our experience shows the polygraph could be used for preemployment testing of candidates for both government and private sector jobs. Also, its preventative usage has been found in loyalty testing of employees, who give informed consent to be tested on regular bases - for example, every 6 months or every year, depending on their position and exposure to risky situations.

Since there is still no law regulating the usage of the polygraph method, the polygraph test results are accepted by Bulgarian courts not by themselves but as part of a psychological expertise. For the preparation of a psychological expertise for the court, it is necessary that the professional is familiar with all case materials [2]: data from the crime scene, interviews with witnesses or witness, crime scene photos, data and reports from other expertise or forensic, ballistic, fingerprint reports etc.

The reason why the polygraph method is respected in Bulgaria is because the examiners are properly trained and many of the criminal cases in the country are resolved with the help of the method - cases of organized crime, rape, murder, armed robberies, missing people, fraud, etc.

The growing interest in the method is the base for the need of training polygraph examiners. This together with the fact that Bulgaria is far more accessible than USA by European, Asian and African countries the Backster School of Lie Detection, Europe was developed. Participating in a 10 week course with APA standards in Sofia is a lot cheaper and easier than to apply for a USA visa, paying expenses for accommodation and travel costs. Moreover, Assess, the representative of Backster School of Lie Detection in Europe, Asia and Africa - is a working business, so all participants in a basic polygraph examiner training course could freely finish their final Projects at the company office after going through the course, an important opportunity for experts who don't have this luxury in their home countries.

The need for the polygraph method will only rise in the coming years, having in mind the processes and the threat for the security of many people worldwide.

\section{References}

1. Zanev, Svetoslav (2002) The polygraph or truth machine.

2. (2013) Collection of Scientific Reports. Institute of Psychology, Ministry of Interior of Bulgaria, Bulgaria. 